\section{Clinical decision-making after endodontic instrument fracture}

\author{
M. B. McGuigan, ${ }^{1}$ C. Louca ${ }^{1}$ and H. F. Duncan*2
}

\author{
IN BRIEF \\ - Considers the management options for \\ separated endodontic files with reference \\ to the evidence base. \\ - Reviews the range of methods available \\ to the clinician to remove files. \\ - Highlights the likelihood of instrument \\ removal in various clinical scenarios and \\ indicates when to refer. \\ - Emphasises the medico-legal aspects of \\ file fracture.
}

When a file fractures during root canal treatment there are several treatment options available to the clinician. The definitive management should be based on a thorough knowledge of the success rates of each treatment option, balanced against potential risks of removal or file retention. Although integration of modern techniques into endodontic practice has improved the clinician's ability to remove fractured files, removal may not always be possible or even desirable. The aim of the third and final review in this series was to analyse the literature with regard to the management of fractured files. Analysis of the literature demonstrated that the presence of a fractured instrument need not reduce the prognosis if the case is well treated and there is no evidence of apical disease. Therefore, in cases without apical disease removal of the file may not be necessary and retention or bypass should be considered. If apical disease is present, file fracture significantly reduces prognosis indicating a greater need to attempt file removal or bypass. A plethora of different methods have been employed to remove fractured instruments and although successful, these techniques usually require the use of the operating microscope and specialist care. Removal of a fractured file is not without considerable risk, particularly in the apical regions of the root canal, therefore, leaving the fragment in situ should be considered if referral is not possible. Finally, it is imperative that the patient is informed (accompanied by appropriate record keeping) if instrument fracture occurs during treatment or if a fractured file is discovered during a routine radiographic examination.

\section{AIM}

In the event of endodontic instrument fracture the clinician has to be prepared to manage the situation both clinically and medico-legally. The clinical decision should be based on a thorough knowledge of the success rates of each treatment option, balanced against potential risks of removal or file retention. A review of the available evidence for each treatment option and clinical decision-making is the subject of the third and final review in this series.

\section{WHAT ARE THE OPTIONS?}

When an instrument fractures in the root canal system a decision has to be made to

\footnotetext{
'Eastman CPD, UCL Eastman Dental Institute, 123 Grey's Inn Road, London, WC1X 8WD; ${ }^{2}$ Division of Restorative Dentistry and Periodontology, Dublin Dental University Hospital, Trinity College Dublin, University of Dublin, Dublin, Ireland

*Corresponding author: Henry F. Duncan

Tel: +353 161 27356; Fax: +353 161 27312;

Email: Hal.Duncan@dental.tcd.ie
}

\section{Refereed Pape}

Accepted 29 October 2012

DOI: 10.1038/sj.bdj.2013.379

${ }^{\circledR}$ British Dental Journal 2013; 214: 395-400 leave, bypass or remove the fragment, the choice being based on an assessment of the potential benefit of removal compared with the risk of complication. The interests of the patient are paramount in this decision as they may opt to have the tooth extracted for reasons such as anxiety, time and finance.

\section{LEAVE FRACTURED INSTRUMENT IN SITU}

Historically, it was recommended that regardless of the preoperative status of the pulp, the fractured instrument should be left in situ and root canal treatment completed coronal to the fragment, before a period of review. ${ }^{1,2}$ It was proposed that the fractured instrument generally did not affect prognosis and could therefore be retained, as the risk of removal was high. It must be stressed, however, that these publications predate the use of the operating microscope and specialised ultrasonic tips, which would limit the risk of complication. Although it was suggested that the retention of the fractured instrument did not affect prognosis, it is logical to assume that the fragment will compromise chemo-mechanical cleansing, working length control and root canal filling. ${ }^{3}$ From the patient's perspective, retaining the fractured i strument can be a source of anxiety as it can be viewed as a treatment failure or even clinical negligence and may be perceived as the source of any problem the patient may encounter in the future. Furthermore, it is difficult for the patient to further invest in a 'compromised' tooth (eg coronal restoration) where the prognosis seems uncertain. Equally, for the clinician, it is often an unsatisfying conclusion to the treatment, which could result in a complaint or medico-legal proceeding and can become a source of contention between a referring dentist and specialist. Conversely, it can be argued that retaining the fragment where appropriate is a less destructive option, conserving tooth substance, time and money.

\section{REMOVE FRACTURED INSTRUMENT}

Recently, it has been suggested that removal should always be attempted, ${ }^{4}$ the fragment only being retained when 
nonsurgical removal has been unsuccessful. ${ }^{5}$ The rationale is (as previously stated) that unless the obstruction in the canal is removed - allowing complete chemomechanical disinfection of the root canal system - outcome will be significantly reduced. ${ }^{3,6}$ Furthermore, it has been reported that in the presence of a periapical lesion, endodontic treatment which is compromised by procedural errors - such as a fractured instrument - demonstrated reduced healing. ${ }^{3,7}$ Obviously, removal should improve working length control - assuming there is minimal canal aberration - and facilitate effective obturation of the root canal system. ${ }^{8}$ Successful removal of the fragment from the tooth also provides psychological benefits for the patient and avoids the risk of medico-legal action (Figs 1a and 1b).

The recent literature does advocate retention of the fractured instrument in selected circumstances, such as file fracture of an instrument in a vital tooth or when chemo-mechanical disinfection is well advanced..$^{9,10}$ The extent of canal disinfection correlates to the stage of instrumentation; logically if an instrument fractures early in the procedure, the canal is less likely to be clean than if a file fractures at the end of instrumentation, however, surprisingly it has not been convincingly demonstrated in the literature that this makes a difference to endodontic prognosis. Ultimately, it is difficult to judge the level of infection in the root canal system before treatment or at a particular stage of cleaning, other than to comment that root canal infection is considered the essential cause of apical periodontitis. ${ }^{11}$

Where conditions are favourable, removal of the retained fragment can be a conservative procedure, ${ }^{12}$ but in cases where access to the fragment is difficult and/or visibility limited, removal may lead to iatrogenic errors such as ledge formation, perforation or excessive enlargement of the canal; this results in a weakened root structure which predisposes to vertical fracture. ${ }^{5,8,13-17}$ Additional complications of removal involve fracture of a second instrument or extrusion of the fractured segment. ${ }^{8}$ If non-surgical removal is not possible, surgical removal of the portion of the root containing the fractured fragment has also been advocated, however this procedure relies on considerable surgical skill and may reduce the crown-root ratio. ${ }^{18}$

\section{BYPASS FRACTURED INSTRUMENT}

Other authors suggest that it is more conservative to bypass the fractured instrument, particularly in cases where access to the fragment is restricted (apical one-third of canal or beyond the canal curvature) and its removal may lead to excessive removal of dentine with associated sequelae. ${ }^{16,19,20}$ Interestingly, it has been reported that if the file is bypassed, the retained fragment does not compromise obturation quality; ${ }^{21}$ however, this observation was made from a leakage study, the clinical relevance of which is questionable. ${ }^{22}$ Notably, it is generally reported if the instrument can be bypassed it can be removed. ${ }^{17,23}$

\section{WHAT OTHER FACTORS INFLUENCE CLINICAL DECISION-MAKING?}

\section{Periodontal and restorative status of tooth}

Periodontally compromised teeth do not make good candidates for instrument removal, although it can be considered if the patient's periodontal condition is stable and they are informed of the risks of removal. In cases where teeth are unrestorable or are likely to become unrestorable subsequent to instrument removal, extraction should be considered, as there is no virtue in spending further resources (patient or dentist) treating a tooth with a hopeless prognosis.

\section{Patient factors}

Fractured instrument removal generally involves a prolonged period in the dental chair, therefore, general dental issues such as patient apprehension and time constraints become more pertinent. Health issues may also alter the balance in favour of instrument removal if extraction is best avoided. Conditions such as severe bleeding disorders or patients receiving intravenous bisphosphonate medication are at increased risk of postoperative complications subsequent to dental extractions. ${ }^{24}$ Finally, cost to the patient may be an influencing factor as removal of fractured files is a technically challenging procedure, often requiring the assistance of a specialist. Patients may decide that removal of the fragment is not worth the additional financial outlay compared to extraction or observation.

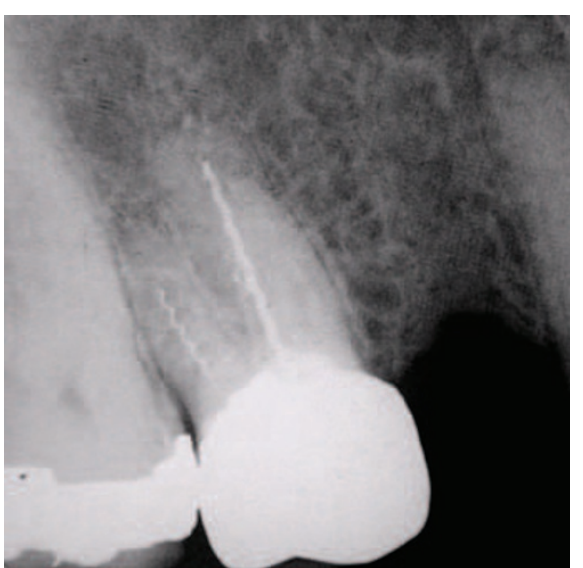

Fig. 1a Preoperative periapical radiograph of tooth 16 demonstrating fractured files in two canals. Periapical radiolucency indicative of apical periodontitis was evident around the roots. The patient was unaware of the presence of the fractured instruments

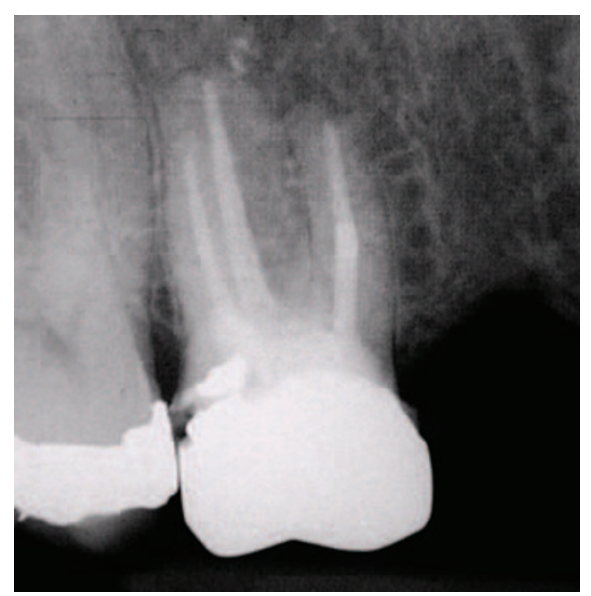

Fig. 1b Postoperative radiograph after removal of the fractured instruments in $\mathbf{1 6}$ and completion of the root canal treatment. In this case removal of the fractured instruments using a ultrasonic agitation did not necessitate significant dentine removal from the canal walls

\section{HOW SUCCESSFUL ARE CLINICIANS AT REMOVING INSTRUMENTS AND WHAT INFLUENCES THAT SUCCESS?}

The likelihood of successful removal of a fractured instrument is reported as ranging from 53 to $95 \% . .^{5,15-17,23,25}$ The wide variation in the reported results can be accounted for by a range of factors which influence the probability of removal. ${ }^{12}$ These factors can be broadly grouped as (1) the location, length and type of fractured instrument, (2) the tooth/canal involved, and (3) the clinician's skill and available armamentarium.

\section{(1) Location, length, type and material of fractured instrument}

Location - With the introduction of the operating microscope into clinical dentistry, 


\begin{tabular}{|c|c|c|c|c|}
\hline $\begin{array}{l}\text { Device } \\
\text { category }\end{array}$ & Method & Manufacturer & Reference(s) & Mechanism of action \\
\hline Ultrasonics & Ultrasonic tips & $\begin{array}{l}\text { Various } \\
\text { manufacturers }\end{array}$ & $\begin{array}{l}\text { Ruddle, } 2004^{12} \\
\text { Ward et al., 20038 } \\
\text { Suter et al., 2005 } \\
\text { Fu et al., } 2011^{40}\end{array}$ & $\begin{array}{l}\text { Creation of a 'staging platform' } \\
\text { around the head of the } \\
\text { fractured file. File removed by } \\
\text { agitation/unwinding. }\end{array}$ \\
\hline \multirow[t]{5}{*}{$\begin{array}{l}\text { Microtube } \\
\text { devices }\end{array}$} & Masserann kit & $\begin{array}{l}\text { Micro-Mega, } \\
\text { Besançon, } \\
\text { France }\end{array}$ & Nagai et al., $1986^{13}$ & $\begin{array}{l}\text { A range of trephine and } \\
\text { extractor (various sizes) } \\
\text { designed to grip the head } \\
\text { of the fractured file. }\end{array}$ \\
\hline & Cancellier kit & $\begin{array}{l}\text { SybronEndo, } \\
\text { CA, USA }\end{array}$ & $\begin{array}{l}\text { Spriggs et al., } \\
1990^{41}\end{array}$ & $\begin{array}{l}\text { A range of tubes which engage } \\
\text { the head of the file with } \\
\text { the aid of a cyanoacrylate } \\
\text { adhesive. Requires initial } \\
\text { creation of a staging platform } \\
\text { with ultrasonic files. }\end{array}$ \\
\hline & Endo Extractor & $\begin{array}{l}\text { Brasseler, } \\
\text { GA, USA }\end{array}$ & $\begin{array}{l}\text { Gettleman et al., } \\
1991^{42}\end{array}$ & $\begin{array}{l}\text { A range of trephines and drills } \\
\text { that accommodate the head } \\
\text { of the instrument. }\end{array}$ \\
\hline & $\begin{array}{l}\text { Meitrac } \\
\text { system }\end{array}$ & $\begin{array}{l}\text { Hager and } \\
\text { Meisinger, } \\
\text { Neuss, Germany }\end{array}$ & Ruddle, 2004'2 & $\begin{array}{l}\text { A range of trephines and } \\
\text { extractors, available as three } \\
\text { kits. The instrument must } \\
\text { initially be freed coronally by } \\
\text { creation of a 'staging platform' }\end{array}$ \\
\hline & $\begin{array}{l}\text { Instrument } \\
\text { Removal } \\
\text { System (iRS) }\end{array}$ & $\begin{array}{l}\text { Dentsply } \\
\text { Maillefer, } \\
\text { Ballaigues, } \\
\text { Switzerland }\end{array}$ & Ruddle, $2002^{43}$ & $\begin{array}{l}\text { A device in two sizes designed } \\
\text { to grip the head of the file. } \\
\text { Requires creation of an ultra- } \\
\text { sonic staging platform in the } \\
\text { first instance. }\end{array}$ \\
\hline $\begin{array}{l}\text { Pliers/ } \\
\text { forceps }\end{array}$ & $\begin{array}{l}\text { Steiglitz } \\
\text { forceps }\end{array}$ & $\begin{array}{l}\text { Various } \\
\text { manufacturers }\end{array}$ & Hülsmann, $1993^{30}$ & $\begin{array}{l}\text { Specialised forceps which } \\
\text { grip the head of the fractured } \\
\text { instrument, only effective if } \\
\text { the fractured instrument is in } \\
\text { the coronal aspect of the canal. }\end{array}$ \\
\hline Other & $\begin{array}{l}\text { Canal finder } \\
\text { system }\end{array}$ & $\begin{array}{l}\text { Endo Technic, } \\
\text { CA, USA }\end{array}$ & Hülsmann, $1994^{44}$ & $\begin{array}{l}\text { Automated reciprocating } \\
\text { device which bypasses or } \\
\text { removes the instrument. }\end{array}$ \\
\hline
\end{tabular}

instruments in the straight portion of the canal can now generally be removed, while fractured instruments that lie partially in the canal curvature - although more challenging - can also be removed. ${ }^{12}$ The bulk of the literature - both in vitro and in vivo studies - agrees that when fragments are localised apical to the canal curvature, removal is compromised, often impossible and generally ill advised..$^{5,8,12,13,15,16}$ One investigator, however, suggested the opposite, reporting no significant difference in success of instrument removal with regard to its position in the canal (the exception being where fragments extended beyond the apex). ${ }^{17}$ Nonetheless, the authors also reported that the potential for perforation was greater when removal was attempted in the apical third of the root canal. ${ }^{17}$

Length - Hülsmann and Schinkel ${ }^{5}$ proposed that longer fragments would be easier to remove than short fragments, explaining that fragments ( $>5 \mathrm{~mm}$ ) were likely to engage dentine at their tips, creating space coronally to allow loosening of the fragment, however, this notion was not demonstrated experimentally. Shen and co-workers ${ }^{15}$ also reported an increase in success of removal of fragments with greater length but again the difference was not significant. Other studies either reported no correlation between fragment length and success of removal or did not investigate length as a variable. ${ }^{17,23}$ Therefore, it can be concluded at present that there is no evidence to suggest that length is a significant variable in fractured instrument removal.

Type - It was previously demonstrated that fractured instrument type had a significant influence on success of removal, with removal of reamers and lentulo spirals proving more successful than Hedström files. ${ }^{5}$ More recent research investigating a broad spectrum of instruments, including hand and rotary files of various designs and taper, concluded that instrument type did not have any effect on success of removal. ${ }^{15,17}$ However, another author concluded that it may be that the number of cases in the relevant subgroups were too small to demonstrate a significant difference. ${ }^{23}$

Material - Stainless steel (SS) files are considered to be easier to remove than nickel-titanium (NiTi) instruments, which have a higher propensity to fracture further during the removal process, perhaps due to accumulation of heat from direct ultrasonic vibration. ${ }^{12}$ Other suggested explanations for the increased difficulty of removing rotary NiTi instruments include the fact that they effectively engage or 'lock' into the canal during rotation and tend to fragment into smaller pieces often at or around the curves of narrow canals. ${ }^{8,17}$ Shen and coworkers ${ }^{15}$ compared the success in removing fractured NiTi instruments (53\%) to an earlier study ${ }^{5}$ reporting on successful removal of fractured SS fragments (59\%) and concluded that removal of NiTi instruments was less successful. They attributed this to different materials, however, several other variables - operator or equipmentbased - make objective comparison impossible. It is logical, however, to suggest that the increasing taper of NiTi compared with SS instruments would practically make access and trephining around the coronal aspect of the NiTi fragment more difficult and therefore harder to remove.

\section{(2) Tooth/canal involved}

Root anatomy such as the diameter, length, canal curvature and thickness of the root dentine has been reported to affect the potential to safely remove a fractured instrument. ${ }^{26}$ There is general agreement that curved canals (particularly buccal canals of maxillary molars and mesial canals of mandibular molars) present a significantly higher risk of instrument fracture than straight canals. ${ }^{5,15,17}$ However, there is conflicting evidence with regard to the influence of the degree of canal curvature on the removal process. Some investigators reported significantly decreased removal rates as the severity of curvature increases, ${ }^{5,15,23}$ suggesting that as the angle of root curvature increases, it becomes technically more difficult to create a 'staging platform' and trephine around the coronal aspect of the fragment, in addition there is a concern regarding insufficient 
thickness of dentine to facilitate such a preparation. Conversely, it was reported that the degree of curvature was not a significant prognostic factor for removal of a fractured fragment, ${ }^{17}$ the investigators suggesting that as long as the coronal aspect is visible/accessible, the degree of curvature of the canal was irrelevant. Unsurprisingly, with regard to specific teeth, single rooted teeth and those with uncomplicated root canal anatomy (eg incisors, canines, palatal roots of maxillary molars) have a higher probability of removal. ${ }^{15,23}$ Predictably, reported success rates drop for the mesiobuccal canals of maxillary molars ${ }^{23}$ and mandibular molars. ${ }^{15}$ Perhaps surprisingly, certain authors reported the poorest removal success rates for maxillary and mandibular premolars, ${ }^{5,15}$ the authors attributing this to narrow root canals and root canal irregularities. By contrast, another study reported no statistical difference in removal success rates with regard to tooth and/or root type. ${ }^{17}$

\section{(3) Clinician's skill and available armamentarium}

The clinician's experience, competence and attitudes regarding the impact of a fractured file on prognosis are important factors in the management of a fractured instrument. ${ }^{12}$ Removal of fractured files is technically demanding and is largely within the remit of an endodontic specialist. Selecting and effectively using the appropriate equipment from the plethora of innovative new technologies and operating them efficiently require experience and judgement (Table 1; Figs 2a-c). Several authors have noted the importance of operator skill and experience on successful removal as well as the negative effect of operator fatigue. ${ }^{5,8,23,27}$ Interestingly, with regard to clinical time spent removing the fragment, studies demonstrate a lower success rate and an increased prevalence of complications when operator time exceeded 45-60 minutes. . $^{8,25}$

In modern endodontic practice fractured instruments can be removed more predictably, which has been credited to technological advances including the use of the dental operating microscope, ultrasonics and microtube extraction devices. ${ }^{12}$ Specifically, it is the direct and illuminated visualisation of the coronal aspect of the fractured instrument afforded by the operating microscope that is deemed essential, allowing the operator to remain centred within the canal thereby reducing the likelihood of enlargement and possible perforation of the canal. ${ }^{8}$ Other studies have verified this, attributing their relatively higher removal success rates (87\% and 95\% respectively) to the use of an operating microscope, ${ }^{17,23}$ when compared to the lower overall success rates of $68 \%$ of an earlier study which did not report using an operating microscope. ${ }^{5}$ However, other factors may account for these differing success rates, including the lack of modern ultrasonic 'tips' and use of different removal systems.

There appears to be no statistically significant difference in removal success rates with respect to different methods of instrument removal. ${ }^{17}$ Relative successes of different techniques are difficult to ascertain experimentally; often a combination of techniques is used in a limited number of patients. Furthermore, a number of the relevant publications are case reports and do not allow for easy comparison with other removal technique data. ${ }^{23}$ What is evident from the literature reporting on fractured instrument removal is that the use of ultrasonics or modified Gates-Gliddens to create a 'staging platform' is the most commonly reported technique. ${ }^{8,28}$

\section{METHODS OF REMOVAL}

If the clinician elects to remove the fractured segment, a wide array of techniques and devices has been developed to facilitate the process. These devices can be broadly categorised as ultrasonics, microtube devices and pliers/forceps (Table 1). ${ }^{12,29}$ It is not within the remit of this discussion to provide an exhaustive list of removal techniques but a short evidence based summary is included.

The success of certain devices has been well documented in the case of ultrasonic removal, ${ }^{8,13,17,25}$ but unfortunately many of the microtube systems have no such scientific evaluation; this presents problems for clinicians in assessing their relative efficacy. All of the techniques share similar problems of excessive dentine removal, weakening of the root structure, predisposition to ledging, perforation or root fracture and possible extrusion of the fragment through the apex. ${ }^{12,13,18,19,30}$ Furthermore, since successful removal requires visualisation and straight-line access to the coronal

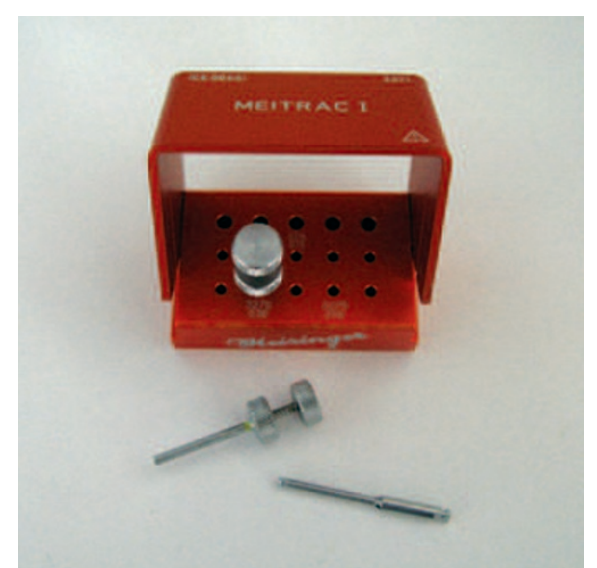

Fig. 2a The Meitrac I Endo Safety System for removal of fractured instruments. This microtube device is designed to engage the coronal aspect of the file facilitating removal

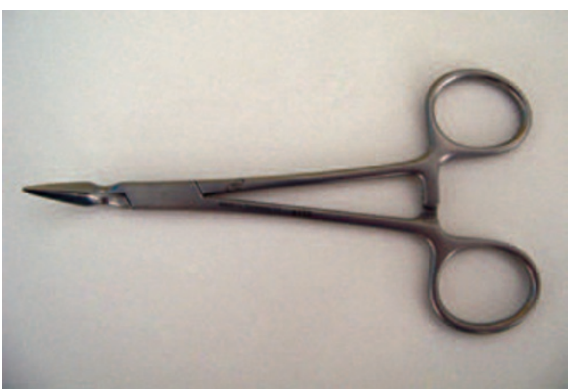

Fig. $2 b$ Steiglitz forceps for removal of easily accessible fragments generally within the pulp chamber

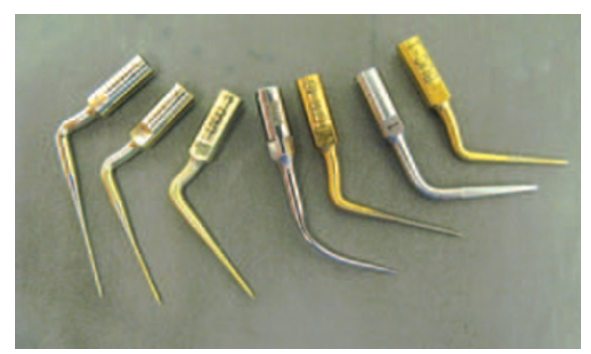

Fig. 2c A selection of commercial ultrasonic tips designed to remove dentine from the root canal system and facilitate file removal

aspect of the fractured instrument, these techniques are generally used in singlerooted teeth or straight roots (Figs 3a-c) and have limited application in narrow and curved segments of the root where there is reduced dentine thickness.

\section{Ultrasonic devices}

Ultrasonics (Fig. 2c), in conjunction with a microscope, are considered the most conservative method of removal and as a result have become the most universally used and investigated technique, both in vitro and in vivo. ${ }^{5,8,13,17,23,25}$ The most commonly described technique involves the creation of a 'staging platform' (classically created 


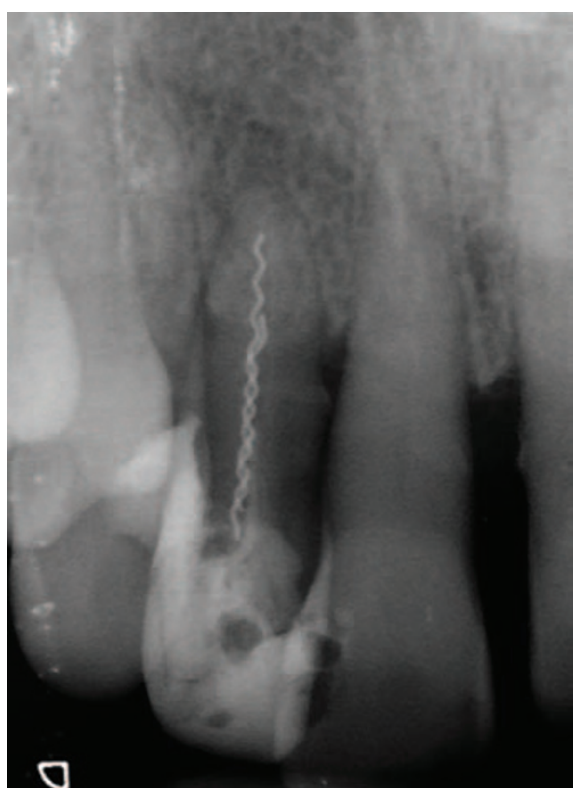

Fig. 3a Preoperative periapical radiograph of tooth 12 demonstrating a suspected fractured instrument in the canal

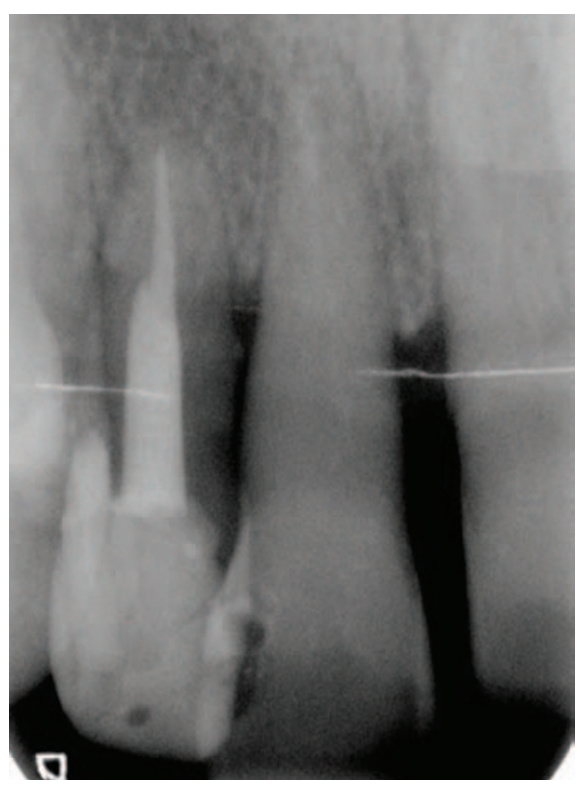

Fig. 3b Postoperative radiograph after removal of the instrument using a combination of ultrasonic agitation and a micro-tubule device

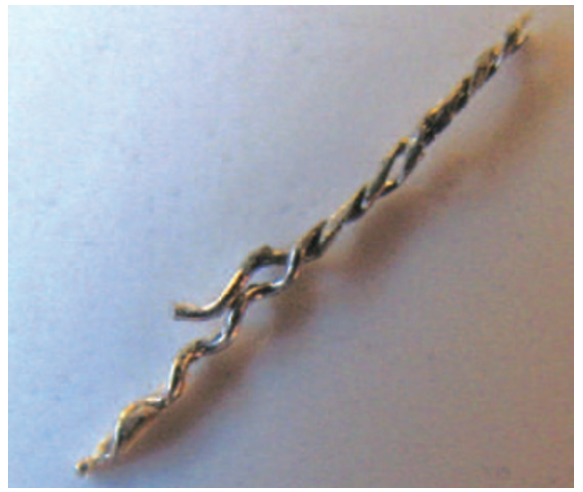

Fig. 3c Photograph of fractured segment revealing two separate instruments intertwined by a modified Gates-Glidden drill although ultrasonic tips can be used), which creates sufficient space to allow the specialised ultrasonic tips to trephine around the coronal aspect of the fragment and in so doing agitating, loosening and unwinding the fractured instrument. ${ }^{31}$ It is generally recommended that a cotton wool plug is placed in the other canal orifices to prevent the removed segment lodging in another canal. Ultrasonic agitation of a modified or unmodified pre-curved K-file has also been described as an alternative method to the use of a specialised tip to create a trough around the coronal aspect of the fragment. ${ }^{13}$ It is suggested that the use of a K-file is more versatile (large array of file sizes), more economic and has particular application where roots are narrow and root dentine thickness limited. ${ }^{29}$

Piezoelectric (rather than magnetostrictive) ultrasonic devices are recommended so that a dry field can be maintained to ensure optimal vision, however frequent irrigation is essential to dissipate heat, remove debris and promote chemomechanical cleansing of the root canal system. ${ }^{29}$ The lowest effective power setting on the ultrasonic device should be used to avoid further fracture of the fragment or the expensive ultrasonic tip. The use of ultrasonics without water coolant has raised some concern with regard to heat generation and subsequent damage to the periodontal tissues. ${ }^{16}$ Heat generation can be controlled however, with judicious selection of an ultrasonic tip (material and size), power setting and application time which have been experimentally demonstrated to affect temperature rise on the external root surface. ${ }^{8,16,32}$ Certainly, during post removal, the potentially deleterious effects of ultrasonic energy (without coolant) on the attachment apparatus has been reported..$^{33}$ However, it is believed that ultrasonic techniques can be safely employed during removal of fractured instruments as the increase in temperature is not sufficient (dentine dampening the heat generated) to cause irreversible damage to the surrounding periodontal tissues. ${ }^{12}$

\section{Microtube extraction}

Microtube extraction generally involves positioning the end of a narrow metal tube over the exposed coronal tip of the fractured instrument, a circumferential trough around the head of the fragment having previously been created by specialised trephine drills supplied with the system [Masserann (Micro-Mega, Besançon, France); Endo Extractor (Brassler, Savannah, GA, USA); Meitrac systems, (Fig. 2a) (Hager and Meisinger, Neuss, Germany)] or ultrasonics [(Cancellier (SybronEndo, Orange, CA USA); iRS (Instrument Removal System, Dentsply Endodontics, Tulsa, OK, USA)]. The tube then engages the fragment mechanically (Masserann, iRS, Meitrac) or retains with the aid of a cyanoacrylate glue (Cancellier, Endo Extractor). The application of such devices is in the main, limited to the straight or coronal section of the canal, with these systems generally being criticised for requiring excessive canal enlargement. ${ }^{12}$

\section{Forceps/pliers}

Steiglitz forceps (Fig. 2b) or plier-type instruments are suitable only in cases where the fragment extends into the pulp chamber and the instrument can engage and grab the coronal aspect of the instrument. ${ }^{5}$ However, if the instrument is within the root canal, it is generally impossible for the pliers to grab the instrument satisfactorily, without destroying any remaining residual coronal tissue in the process.

\section{Other methods}

Other reported methods for instrument removal include the simple use of chelating agents such as EDTA in combination with stainless steel hand files, ${ }^{12}$ or the use of a hypodermic needle to manually trephine around the coronal aspect of the fragment. ${ }^{34}$ These methods however, are largely anecdotal, practised by a small group of clinicians who have refined this skill rather than being a generally recommended technique. Another reported system is the Canal Finder System (Endo Technic, CA, USA), a reciprocating device that connects to the air motor and can bypass or remove the instrument, however, this has again been largely reported by the experiences of one author. ${ }^{29}$ With regards to developments in the future, laser (pulsed Nd:YAG laser irradiation) has been described as a possible technique for removing/melting the fractured fragment while causing minimal removal of surrounding root dentine. However, substantial research is required into the effects of this technique on the adjacent periodontal tissue and to establish 
adequate safety parameters, before clinical use can be advocated. ${ }^{35}$

\section{MEDICO-LEGAL CONSIDERATIONS}

It is considered good practice for the clinician to inform the patient preoperatively of the options and risks of treatment as part of the consent procedure. Theoretically therefore, every patient undergoing endodontic treatment or retreatment should be warned of the possibility of file fracture. However, it is questionable as to whether this happens in practice.

The incidence of instrument fracture is reported to be relatively low (0.7-7.4\%) $)^{1,10,36-}$ ${ }^{38}$ and the effect of instrument fracture on outcome is largely reported as insignificant; it therefore seems questionable as to whether the patient should be warned of the risk of fracture when they are not routinely warned of the risk of other factors such as poor endodontic treatment, which has been shown to have a negative effect on prognosis. ${ }^{10,39}$

Nevertheless, the stressful event of fracture becomes more difficult to defend and manage if the patient has not been informed of the potential risk or indeed of the presence of a fractured instrument in their root canal. What is certain is the fact that clinicians have a legal obligation to inform the patient - and document it in the patient's notes - if an instrument has fractured during treatment. If removal is deemed the most suitable option, again the patient needs to be informed of the associated risks and an appropriate referral made. In the event of retaining the file, radiographic periodic review is necessary to enable early interception should any associated periapical pathology develop (Figs 1a-b).

\section{CONCLUSIONS}

- Fractured instruments can be removed by a variety of methods such as fine ultrasonic tips, micro-tubule devices and pliers/haemostatic forceps

- Although many of these techniques have been described as successful, they require skilled use of the operating microscope and generally considered within the remit of the endodontic specialist

- As removal of a fractured file is associated with considerable risk, bypassing the fragment should be considered

- The removal of files can be expensive in terms of time and equipment and therefore a cost-benefit analysis of the treatment should be considered before selecting a definitive treatment for the patient

- Patients should be informed if an instrument fractures during treatment or if a fractured file is discovered during a routine radiographic examination. It is essential legally that the treatment details and the information given to the patient are recorded accurately in the patient's notes.

1. Crump M C, Natkin E. Relationship of a broken root canal instrument to endodontic case prognosis: a clinical investigation. J Am Dent 1970; 80: 1341-1347.

2. Fox J, Moodnik R M, Greenfield E, Atkinson J S. Filling root canals with files: radiographic evaluation of 304 cases. N Y State Dent J 1972: 38: 154-157

3. Sjögren $U$, Hagglund B, Sunqvist $G$, Wing K. Factors affecting the long-term results of endodontic treatment. J Endod 1990; 16: 498-504.

4. Machtou P, Reit C. Non-surgical retreatment. In Bergenholtz G, Hørsted-Bindslev P, Reit C (eds). Textbook of endodontology, 1st ed. pp 300-310. Oxford: Blackwell Munksgaard, 2003.

5. Hülsmann M, Schinkel I. Influence of several factors on the success or failure of removal of fractured instruments from the root canal. Endod Dent Traumatol 1999; 15: 252-258.

6. Kerekes K, Tronstad L. Long-term results of endodontic treatment performed with a standardized technique. J Endod 1979; 5: 83-90.

7. de Chevigny C, Dao T T, Basrani B R et al. Treatment outcome in endodontics: the Toronto study-phase 4. J Endod 2008; 34: 258-263

8. Ward J R, Parashos P, Messer H H. Evaluation of an ultrasonic technique to remove fractured rotary nickel-titanium instruments from root canals: clinical cases. J Endod 2003; 29: 764-767.

9. Torabinejad M, Lemon R R. Procedural accidents. In Walton R, Torabinejad M (eds). Principles and practice of endodontics, $3^{\text {rd }}$ ed. pp 310-330. Philadelphia: Saunders, 2002.

10. Parashos P, Messer H H. Rotary NiTi instrument fracture and its consequences. J Endod 2006: 32: 1031-1043.

11. Bergenholtz G, Dahlén G. Advances in the study of endodontic infections: introduction. Endod Topics 2004; 9: 1-4.

12. Ruddle C J. Nonsurgical retreatment. J Endod 2004; 30: 827-845.

13. Nagai O, Yani N, Kayaba Y, Kodama S, Osada T. Ultrasonic removal of broken instruments in root canals. Int Endod J 1986; 19: 298-304.

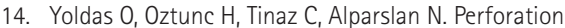
risk associated with the use of Masserann endodontic kit drills in mandibular molars. Oral Surg Oral Med Oral Pathol Oral Radiol Endod 2004; 17: 513-517.

15. Shen Y, Peng B, Shun-pan G, Chueng G S. Factors associated with the removal of fractured NiTi instruments from root canal systems. Oral Surg Oral Med Oral Pathol Oral Radiol Endod 2004; 98: 605-610.

16. Souter N J, Messer H. Complications associated with fractured file removal using an ultrasonic technique. J Endod 2005; 31: 450-452.

17. Suter B, Lussi A, Sequeira P. Probability of removing fractured instruments from root canals. Int Endod J 2005; 38: 112-123.

18. Fors U G H, Berg J O. Endodontic treatment of root canals obstructed by foreign objects. Int Endod J 1986; 19: 2-10.

19. Madarati A, Qualtrough A J, Watts DC. A microcomputed tomography scanning study of root canal space: Changes after the ultrasonic removal of fractured files. J Endod 2009; 35: 125-128.
20. Madarati A, Qualtrough A J, Watts D C. Vertical fracture resistance of roots after ultrasonic removal of fractured instruments. Int Endod J 2010; 43: 424-429.

21. Saunders J, Eleazer $P$, Zhang $P$, Michalek S. Effect of a separated instrument on bacterial penetration of obturated root canals. J Endod 2004; 30: 177-179.

22. Kim Y K, Grandini S, Ames J M et al. Critical review on methacrylate resin-based root canal sealers. J Endod 2010; 36: 383-399.

23. Cujé J, Bargholz C, Hülsman M. The outcome of retained instrument removal in a specialist practice. Int Endod J 2010; 43: 545-554.

24. McLeod N M, Davies B J, Brennan P A. Bisphosphonate osteonecrosis of the jaws; an increasing problem for the dental practitioner. Br Dent J 2007; 203: 641-644.

25. Alomairy K H. Evaluating two techniques on removal of fractured rotary nickel-titanium endodontic instruments from root canals; an in vitro study. J Endod 2009; 35: 559-562.

26. Rhodes J S, Pitt Ford T R, Lynch P J, Liepins P J, Curtis R V. Micro-computed tomography: a new tool for experimental endodontology. Int Endod 1999; 32: 165-170.

27. Terauchi Y, O'Leary L, Kikuchi I et al. Evaluation of the efficiency of a new file removal system in comparison with two conventional systems. J Endod 2007; 33: 585-587.

28. Ruddle $C \mathrm{~J}$. Micro-endodontic nonsurgical retreatment. Dent Clin North Am 1997; 41: 429-454.

29. Cheung G S. Instrument fracture: mechanisms, removal of fragments, and clinical outcomes. Endod Topics 2009: 16: 1-26.

30. Hülsmann M. Methods of removing metal obstructions from the root canal. Endod Dent Traumatol 1993: 9: 223-237.

31. Ruddle C J. Removal of broken instruments. Endod Practice 2003; 6: 13-22.

32. Madarati A, Watts D C, Qualtrough A J. Factors affecting temperature rise on the external root surface during ultrasonic retrieval of intracanal separated files. J Endod 2008; 34: 1089-1092.

33. Gluskin A, Ruddle C J, Zinman E. Thermal injury through intraradicular heat transfer using ultrasonic devices. Precautions and practical preventive strategies. J Am Dent Assoc 2005; 136: 1286-1293.

34. Eleazer P D, O'Connor R P. Innovative uses for hypodermic needles in endodontics. J Endod 1999; 25: 190-191.

35. Yu D G, Kimura Y, Tomita Y, Nakamura Y, Watanabe $H$, Matsumoto K. Study on removal effects of filling materials and broken files from root canals using pulsed Nd: YAG laser. J Clin Laser Med Surg 2000; 18: 23-28.

36. Bergenholtz G, Lekholm U, Milthon R, Heden G, Ödesjö B, Engström B. Retreatment of endodontic fillings. Scand J Dent Res 1979; 87: 217-224.

37. Pettiette M T, Delano O, Trope M. Evaluation of success rate of endodontic treatment performed by students with stainless-steel K-files and nickeltitanium hand files. J Endod 2001; 27: 124-127.

38. Spili P, Parashos P, Messer H H. The impact of instrument fracture on outcome of endodontic treatment. J Endod 2005; 31: 845-850.

39. Kirkevang L, Vaeth $M$, Wenzel. Tooth-specific risk indicators for apical periodontitis. Oral Surg Oral Med Oral Pathol Oral Radiol Endod 2004: 97: 739-744

40. Fu M, Zhang Z, Hou B. Removal of broken files from root canals by using ultrasonic techniques combined with a dental microscope: a retrospective analysis of treatment outcome. J Endod 2011; 37: 619-622.

41. Spriggs K, Gettleman B, Messer H H. Evaluation of a new method for silver point removal. J Endod 1990; 16: 335-338.

42. Gettleman B H, Spriggs K A, EIDeeb M E, Messer $\mathrm{H}$ H. Removal of canal obstructions with the Endo Extractor. J Endod 1991; 17: 608-611.

43. Ruddle C J. Finishing the apical one-third: endodontic considerations. Dent Today 2002; 21: 66-73.

44. Hülsmann M. Removal of fractured instruments using a combined automated/ultrasonic technique. J Endod 1994; 20: 144-147. 